\title{
X-radiation enhances the collagen type I strap formation and migration potentials of colon cancer cells
}

\author{
Stephanie Blockhuys ${ }^{1,3}$, Na Liu ${ }^{1}$, Nisha Rani Agarwal ${ }^{3}$, Annika Enejder³, Vesa Loitto ${ }^{2}$, \\ Xiao-Feng Sun ${ }^{1}$ \\ ${ }^{1}$ Department of Oncology and Department of Clinical and Experimental Medicine, Linköping University, Linköping, Sweden \\ ${ }^{2}$ Medical Microbiology, Department of Clinical and Experimental Medicine, Linköping University, Linköping, Sweden \\ ${ }^{3}$ Molecular Microscopy, Department of Biology and Biological Engineering, Chalmers University of Technology, Gothenburg, Sweden \\ Correspondence to: Xiao-Feng Sun, email: xiao-feng.sun@liu.se \\ Stephanie Blockhuys, email: steblo@chalmers.se
}

Keywords: collagen type 1 , colorectal cancer, $X$-radiation, cell migration, integrin $\beta 1$

Received: March 17, $2016 \quad$ Accepted: September 13, $2016 \quad$ Published: September 19, 2016

\section{ABSTRACT}

Rectal cancer treatment still fails with local and distant relapses of the disease. It is hypothesized that radiotherapy could stimulate cancer cell dissemination and metastasis. In this study, we evaluated the effect of X-radiation on collagen type I strap formation potential, i.e. matrix remodeling associated with mesenchymal cell migration, and behaviors of SW480, SW620, HCT116 p53 ${ }^{+/+}$and HCT116 $\mathrm{p} 53^{-/-}$colon cancer cells. We determined a radiation-induced increase in collagen type I strap formation and migration potentials of SW480 and HCT116 p53 $3^{+/+}$. Further studies with

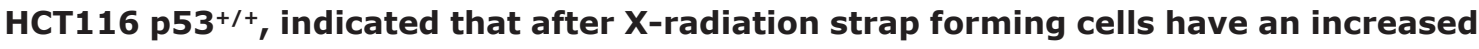
motility. More, we detected a decrease in adhesion potential and mature integrin $\beta 1$ expression, but no change in non-muscle myosin II expression for HCT116 ${\mathrm{p} 53^{+/+}}^{+/}$ after X-radiation. Integrin $\beta 1$ neutralization resulted in a decreased cell adhesion and collagen type $I$ strap formation in both sham and $X$-radiated conditions. Our study indicates collagen type I strap formation as a potential mechanism of colon cancer cells with increased migration potential after $\mathrm{X}$-radiation, and suggests that other molecules than integrin $\beta 1$ and non-muscle myosin II are responsible for the radiation-induced collagen type I strap formation potential of colon cancer cells. This work encourages further molecular investigation of radiation-induced migration to improve rectal cancer treatment outcome.

\section{INTRODUCTION}

Surgery is the mainstay of curative rectal cancer treatments, and radiotherapy in combination with chemotherapy significantly decreases local relapse and improves overall survival [1]. However, treatment failure with local and distant recurrence of the disease is still a major clinical problem [2,3]. Besides the therapeutic effect, radiation may as well stimulate cancer metastasis via various molecular mechanisms $[4,5]$. Cancer cell migration is a key process of metastasis [6] and the mechanistic elucidation of radiation-induced (RI) migration is crucial to improve rectal cancer treatment outcome.

During cancer metastasis, cancer cells migrate through a heterogeneous tumor microenvironment according a mesenchymal or amoeboid pattern. Mesenchymal migrating cancer cells actively remodel their surrounding matrix by deposition of new extracellular matrix (ECM), degradation of existing ECM components and ECM protein fiber alignment. Hereby, collagen type 1 (col-I) fiber alignment, also called col-I strap formation (SF), results from the cell traction force, whereby the cell pulls the col-I fibers into bundles close around itself in order to migrate. In contrast, amoeboid migrating cells do not rely on matrix remodeling for propagation [7].

Integrins are bidirectional communicators between the intracellular cytoskeleton and the ECM proteins. Integrin-mediated signaling pathways control metastasisrelated processes like cancer cell migration [8], and multiple integrins and associated cytoplasmic kinases (FAK, ERK) are upregulated by radiation in relation with a higher aggressiveness of the cancer cells $[9,10,11,12]$. 
Non-muscle myosin II (NMMII) is an important regulator of cell adhesion, migration and matrix organization [13]. NMMII isoforms A and B have distinct roles in matrix organization [14], while NMMII isoform C plays an essential role in cytokinesis [15].

Previously, Blockhuys et al. described an increased col-I SF potential of breast cancer cells after X-radiation. They reported that integrin $\beta 1$ functionality is essential for col-I SF by breast cancer cells after radiation, and that the RI increase in col-I SF potential of breast cancer cells is dependent on an increased NMMIIA expression level [16].

In this study, we evaluated the effect of X-radiation on the col-I SF potential of different colon cancer cell lines and their related behaviors. SW480 and SW620 cell lines, which originate from a primary colon adenocarcinoma and a positive lymph node obtained one year later from the same patient, respectively, facilitated the investigation of mesenchymal and amoeboid cell migration patterns, respectively $[17,18]$. The two HCT116 cell lines, HCT116 p53 $3^{+/+}$(p53 wild type) and HCT116 p53 ${ }^{-/}$(p53 null; p53 gene was disrupted by homologous recombination), elucidated the role of p53 in the radiation response of colon cancer cells [19]. Our study indicates that col-I SF is a potential mechanism of colon cancer cells with increased migration potential after X-radiation.

\section{RESULTS}

\section{X-radiation enhanced col-I SF potential of different colon cancer cells}

Cell-induced col-I straps were visualized using three microscopy techniques: phase-contrast microscopy (PCM), scanning electron microscopy (SEM), and labelfree non-linear microscopy (NLM), namely, second harmonic generation (SHG) for visualization of col-I in combination with two-photon excitation fluorescence (TPEF) for cells. The images presented in Figure 1A illustrate col-I SF by SW480 cells, where col-I fibers are organized as parallel aligned col-I fibers originating from the cellular extensions with a perpendicular orientation towards the cell periphery. In addition to the two-dimensional (2D) overview of the in vitro system obtained by PCM and SEM, NLM acquisition resulted in a three-dimensional (3D) visualization of cell-induced col-I matrix remodeling (Supplementary Figure 1A).

Quantitative evaluation of col-I SF using PCM indicated a significantly higher col-I SF potential of SW480 vs. SW620 cells $(P<0.001)$, and a significantly lower col-I SF potential of HCT116 p53 $3^{+/+}$vs. HCT116 p53 ${ }^{-/-}$cells $(P<0.001)$. After 5 Gy X-radiation, col-I SF potentials of both SW480 and HCT116 p53 ${ }^{+/+}$cells were significantly increased $(P=0.009$ and $P=0.039$, respectively). Furthermore, X-radiation did not significantly change the col-I SF potentials of SW620 and HCT116 p53 cells (Figure 1B). An X-ray dose-dependency study with
SW480 and HCT116p53 $53^{+/+}$cells indicated 5 Gy as the $\mathrm{X}$-ray dose with significantly increased col-I SF potentials of both cell lines $(P<0.001$ and $P=0.013$, respectively; Supplementary Figure 2).

Further functional implications of col-I SF by colon cancer cells were studied by the $3 \mathrm{D}$ col-I contraction assay, whereby col-I matrix contraction reflected the cell traction force applied to the col-I matrix. As shown in Supplementary Figure 1B, the RI increase in col-I matrix remodeling was confirmed by a trend of increased col-I matrix contraction for both HCT116 p53 $3^{+/+}$and HCT116 $\mathrm{p} 53^{-/-}$cells after X-radiation. No results could be presented for SW480 and SW620 cells. The experimental set up was not feasible for the SW cells, since they did not intercalate in the col-I matrix during col-I polymerization.

\section{RI increase in col-I SF potential related with increased motility of different colon cancer cell lines}

The $15 \mathrm{~h}$ PCM time-series demonstrated the heterogeneity in colon cancer cell behavior and related changes in the col-I matrix. Col-I SF was observed as a dynamic process orchestrated by the cells, where col-I straps appeared and disappeared over time. Moreover, the col-I straps were generally formed in between two cells and promoted the migration of the cells towards each other. Representative videos and final PCM images for sham and X-radiated

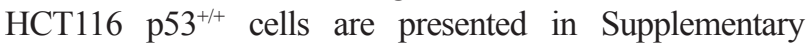
Videos 1-2 and Supplementary Figure 3A-3B, respectively. In addition to col-I SF, we observed two other phenomena: (1) col-I matrix degradation by SW480 cells (Supplementary Video 3), and (2) long distance movement of a large (leader) cell accompanied by a small (follower) cell for X-radiated HCT116 p53 $3^{+/+}$cells (Supplementary Video 4).

Single cell tracking analysis, presented as WindRose plots in Figure 2A, illustrates the increase in cell motility associated with col-I SF potential for SW480 in sham or X-radiated condition and for HCT116 p53 $3^{+/+}$ in X-radiated condition only, but not for HCT116 ${\mathrm{p} 53^{-/-}}^{-1}$ and SW620, in either sham or X-radiated condition, and HCT116 p53 $3^{+/+}$in sham condition. Further quantitative evaluation of the cell tracks supported a direct relationship between the Wind-Rose plots and the cell motility-related parameters cell speed, accumulated - and Euclidean distances. More precisely, we measured a trend of increased speed, accumulated - and Euclidean distances for SF vs. non-SF SW480 in both sham and X-radiated conditions, and a significant increase in speed $(P=0.046)$ and Euclidean distance $(P=0.017)$ for SF vs. non-SF HCT116 p53 $3^{+/+}$cells in X-radiated condition (Figure 2B).

Comparison of the motility of the four cell lines in sham condition indicated a trend of lower motility for SW620 in comparison to SW480 and HCT116 cells. After X-radiation, we observed a trend of increased speed (Supplementary Figure 4A), accumulated distance (Supplementary Figure 4B) and Euclidean distance 
(Supplementary Figure 4C) for SW480 and HCT116 $\mathrm{p} 53^{--}$, but not for HCT116 p53 $3^{+++}$and SW620 cells.

\section{$\mathrm{X}$-radiation decreased adhesion but increased migration of different colon cancer cell lines}

The col-I adhesion potential was not different between SW480 and SW620 cells or between HCT116 $\mathrm{p} 53^{+++}$and HCT116 $\mathrm{p} 53^{-/-}$cells, but a significant decrease in adhesion was observed for HCT116 vs. SW cells $(P=0.002)$. Irradiation did not change the adhesion

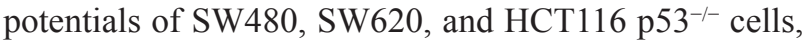
but resulted in a significant decrease in adhesion of HCT116 p53 $3^{+/+}$cells $(P=0.006)$ (Figure $\left.3 \mathrm{~A}\right)$.

The col-I migration potential was not different between SW480 and SW620 cells or between HCT116 p53 $3^{+/+}$and HCT116 $\mathrm{p} 53^{-/-}$cells, but a significant increase in migration was observed for HCT116 vs. SW cells $(P<0.001)$. Irradiation did not change the migration potentials of SW620 and HCT $116 \mathrm{p} 53^{-/-}$cells, but resulted in a significant increase in migration of SW480 and HCT116 p53 $3^{++}$cells $(P=0.001$ and $P=0.004$, respectively) (Figure 3B).

\section{Integrin $\beta 1$ functionality was essential for col-I adhesion and SF by colon cancer cells after $\mathrm{X}$-radiation}

Integrin $\beta 1$ expression analysis indicated that integrin $\beta 1$ expression levels were higher in HCT116 than in SW cells. In sham condition, a trend of higher expression of the mature form of integrin $\beta 1(\mathrm{MW}=115 \mathrm{kDa})$ was
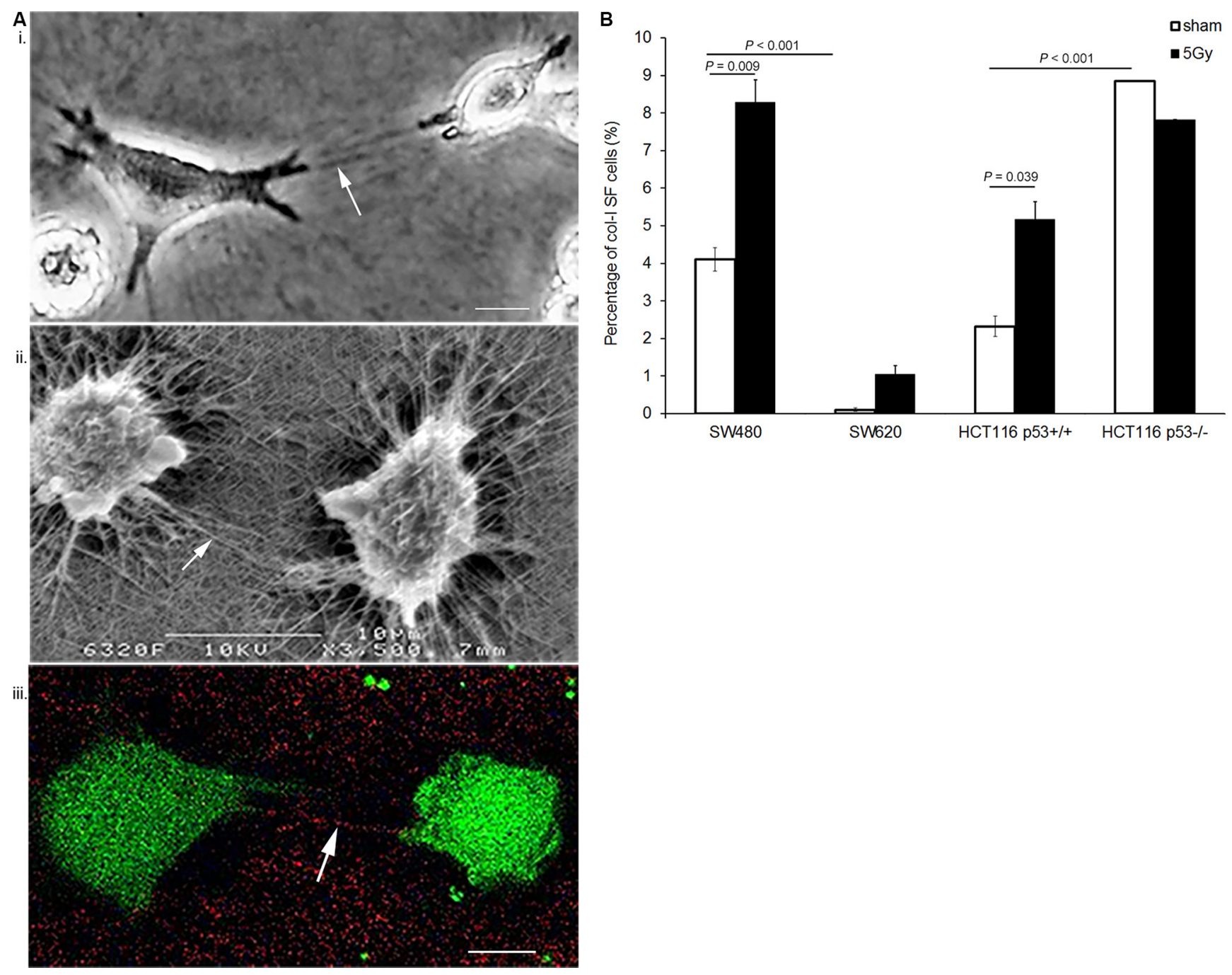

Figure 1: X-radiation enhanced col-I SF potential of various colon cancer cell lines. (A) Visualization of col-I straps induced by SW480 cells in the col-I matrix assay: (i) phase-contrast microscopy (PCM), (ii) scanning electron microscopy (SEM), and (iii) second harmonic generation (SHG; red color) in combination with two-photon emission fluorescence (TPEF, green color). Visualization of the col-I straps by SHG confirmed the col-I specificity of the straps. (Arrows indicate col-I straps; scale bar $=10 \mu \mathrm{m}$ ). (B) Quantification of col-I SF potential of four colon cancer cell lines at day 5 after sham or 5 Gy X-radiation. Error bar represents the standard error of the mean $\left(n_{\text {IrExp }}=3 ; t\right.$-test $)$. 
detected in SW480 vs. SW620 cells (100\% vs. 65\%, respectively), and a significantly higher expression of mature integrin $\beta 1$ was determined for HCT116 p53 ${ }^{+/+}$vs. HCT116 p53 $3^{--}$cells $(100 \%$ vs. $36 \% ; P=0.002)$. After $\mathrm{X}$-radiation, a significant decrease in mature $\beta 1$ integrin expression was observed for HCT116 p53 $3^{+/+}$(100\% vs. $27 \% ; P=0.001)$, but no change for SW480, SW620, or HCT116 p53 ${ }^{-/-}$cells (Figure 4A and 4B).

Further investigation of the role of integrin $\beta 1$ in

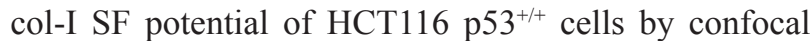
microscopy, indicated an accumulation of integrin $\beta 1$ at the tip of the cell protrusions connected to the col-I strap (Figure 4C). Functional inhibition of integrin $\beta 1$ using a neutralizing antibody reduced the adhesion $(P=0.027$ in sham condition; Figure 4D) and SF potentials $(P<0.001$;

A

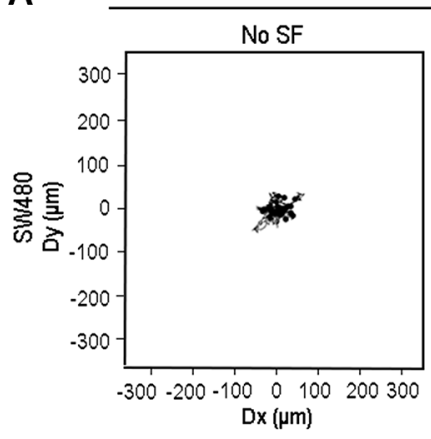

sham
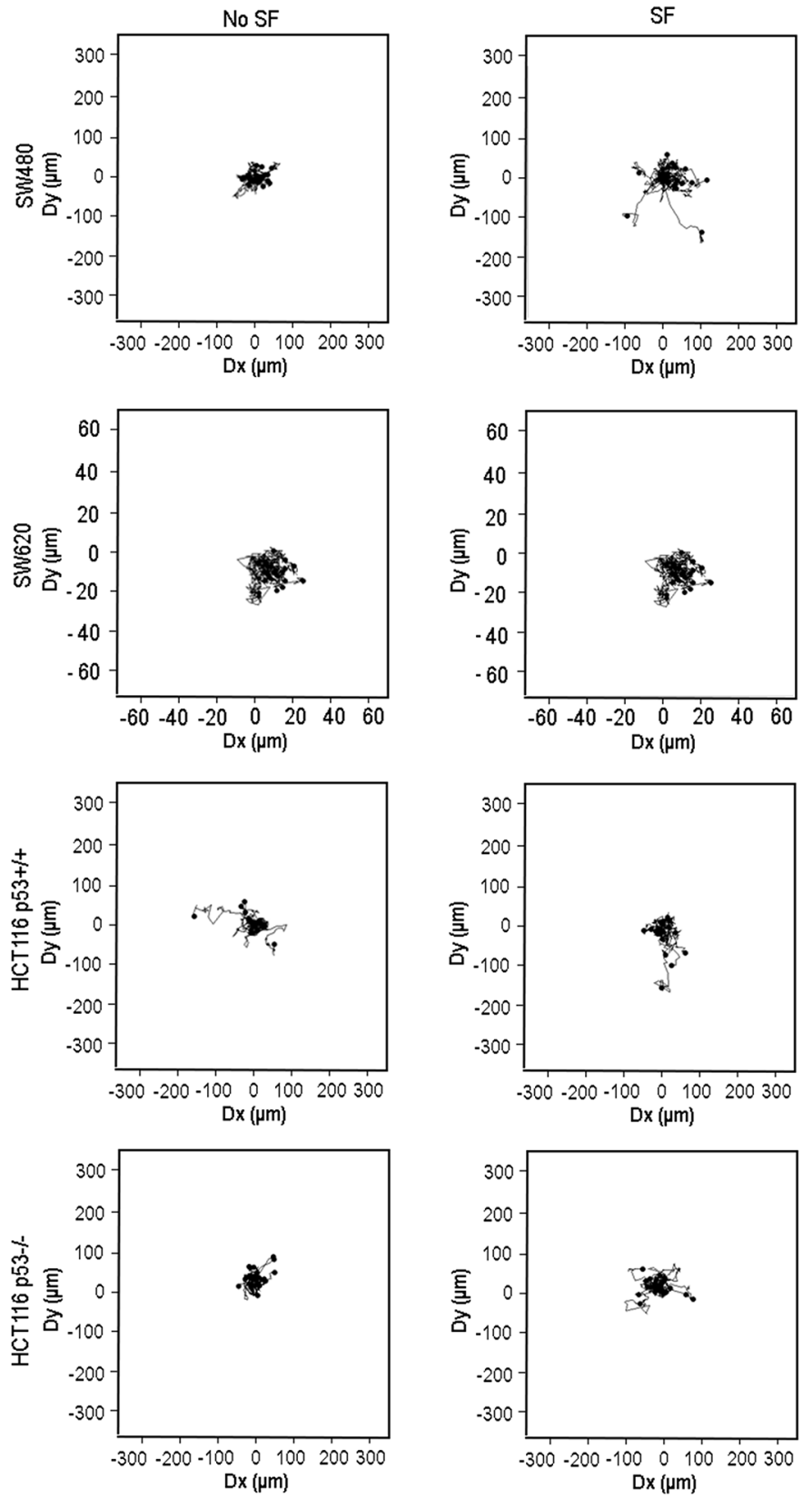

Figure 4E) of HCT116 $\mathrm{p} 53^{+/+}$cells in both sham and $\mathrm{X}$-radiated conditions.

\section{$\mathrm{X}$-radiation did not induced significant changes in MLC2 or NMHCIIA, -B, and -C expression}

MLC2 expression was significantly higher in HCT116 p53 $3^{+/+}$than in HCT116 p53 $3^{-/-}$cells $(P=0.004)$. $\mathrm{X}$-radiation resulted in a trend of increased and decreased MLC2 expressions in SW and HCT116 cells, respectively (Figure 5A and 5B). Under sham conditions, NMHCIIA was detected in all cell lines, NMHCIIB was detected in SW620 cells only, and NMHCIIC was detected in all cell lines except of SW620 cells. After X-radiation, no change in expression of the myosin II isoforms was detected in the

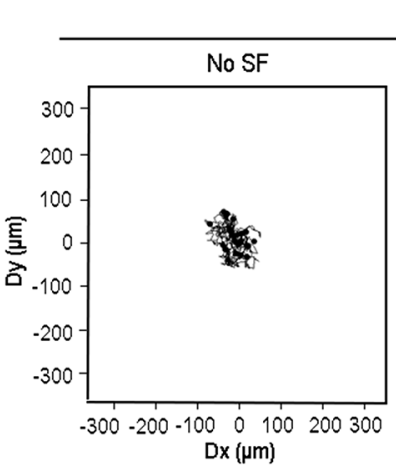

5 Gy
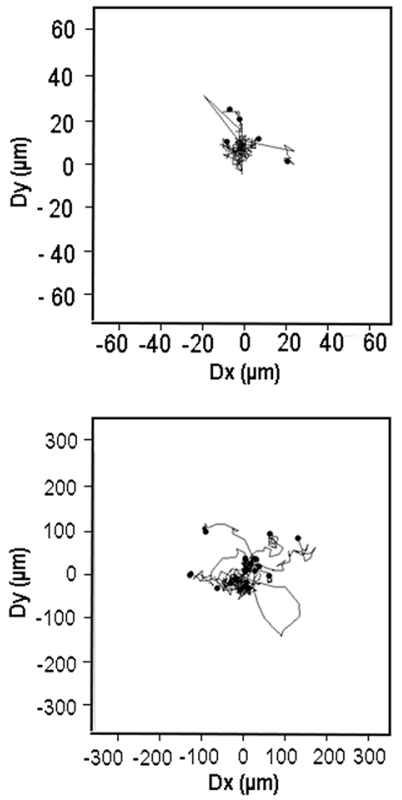
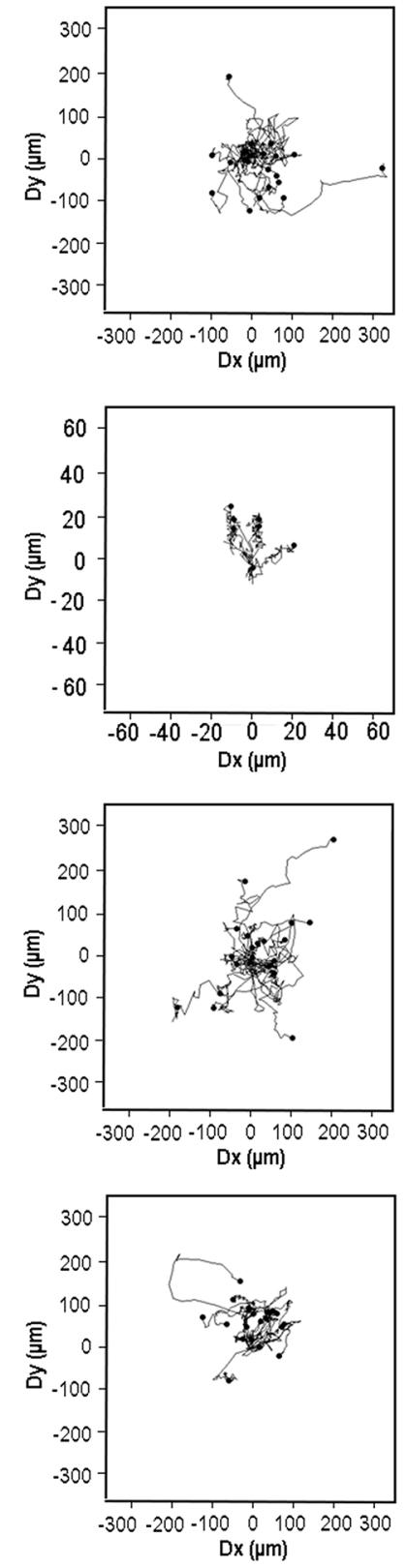

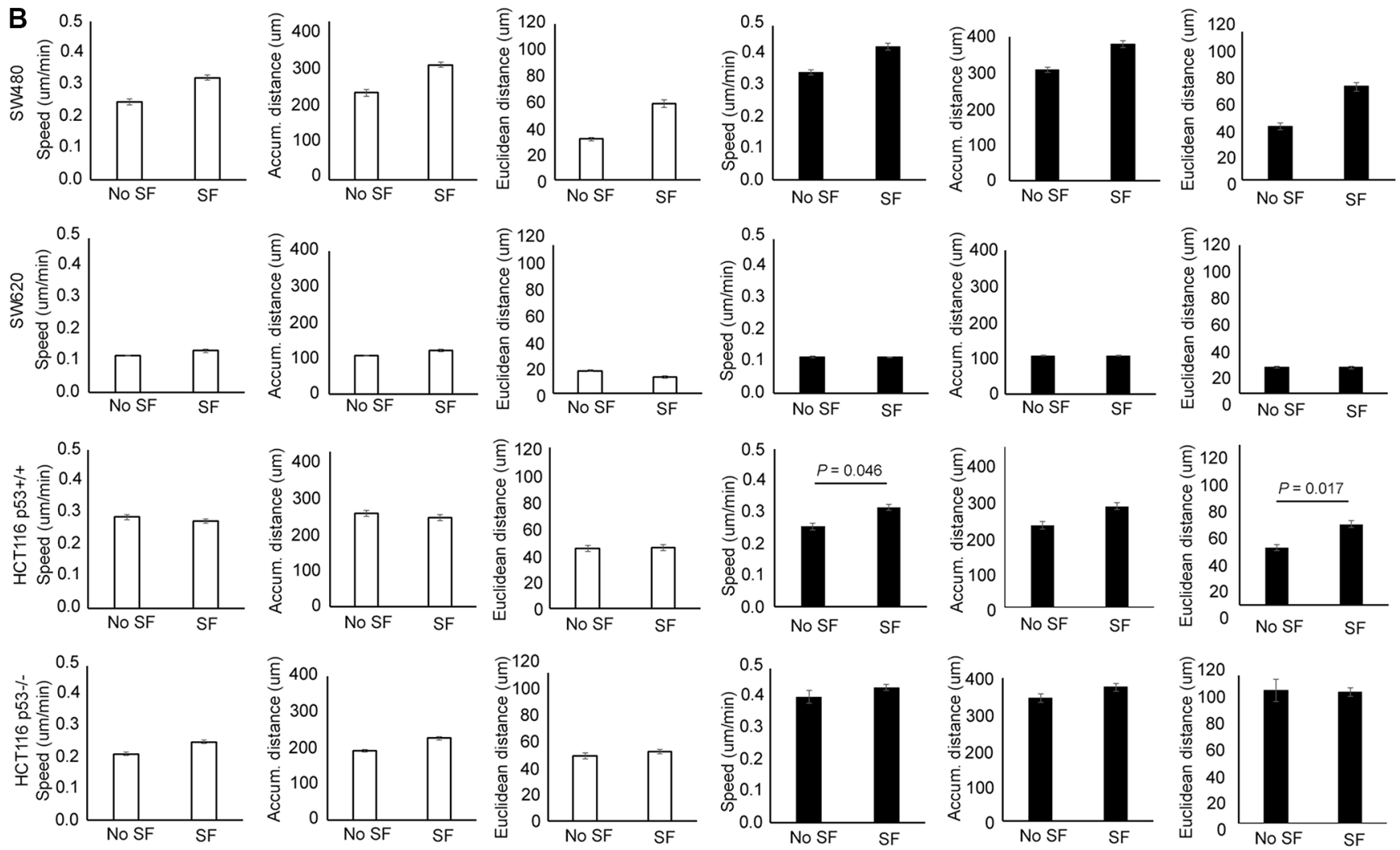

Figure 2: Radiation-induced increase in col-I SF potential was related with increased motility of the tested colon cancer cell lines. (A) Wind-Rose plots presenting the tracks of randomly selected cells without (No SF) and with (SF) col-I SF potential during the $15 \mathrm{~h}$ time-series performed with both sham and X-radiated colon cancer cells $\left(n_{\text {cells }}=20\right.$ for all conditions, except of SW620 5 Gy with $n_{\text {cells }}=7$ ). (B) Mean speed, accumulated distance (Accum. distance) and Euclidean distance of cells without (No SF) and with (SF) col-I SF potential during the $15 \mathrm{~h}$ time-series performed with both sham and X-radiated colon cancer cells. Error bar represents the standard error of the mean $\left(n_{\text {IrExp }}=1\right.$ for SW480, SW620 and HCT116 p53 $3^{-/-}$cells; $n_{\text {IrExp }}=3$ for HCT116 p53 $3^{+/+}$cells; $t$-test performed for HCT116 p $53^{+/+}$cells only).
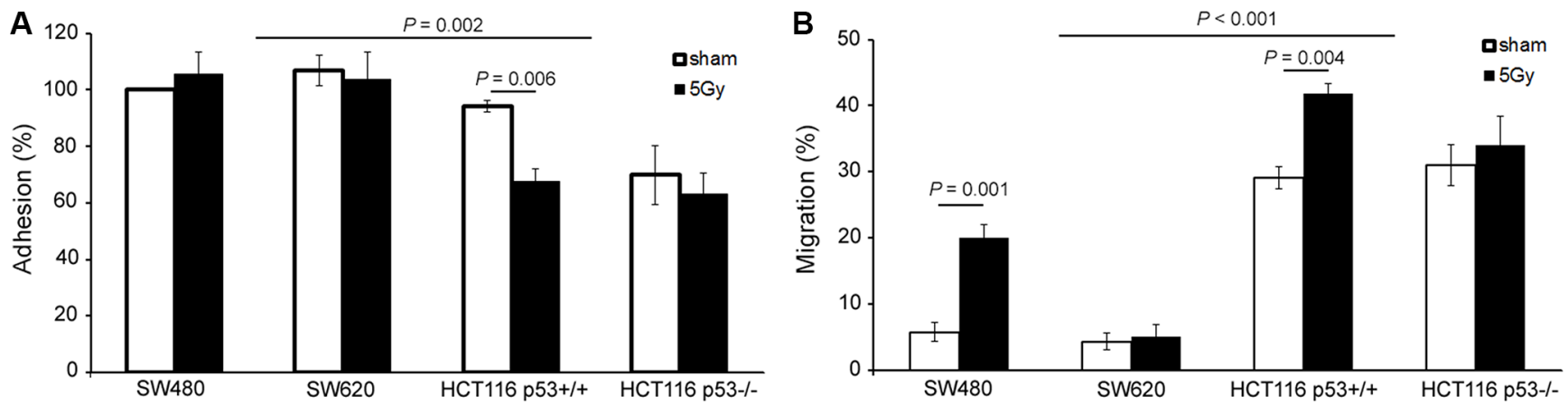

Figure 3: X-radiation decreased adhesion, but increased migration potential of the elucidated colon cancer cell lines. (A) Cell adhesion potential determined by standard cell adhesion assay on col-I coating. Error bar represents the standard error of the mean $\left(n_{\text {IrExp }}=3, t\right.$-test). (B) Cell migration potential determined by the zone exclusion assay on col-I coating. Error bar represents the standard error of the mean $\left(n_{I r E x p}=3, t\right.$-test $)$. 
tested cell lines, apart from a RI expression of NMHCIIC in SW620 cells (Figure 5C and 5D).

\section{DISCUSSION}

Our study indicated col-I SF as a mechanism upregulated by colon cancer cells with increased migration potential after X-radiation. We observed higher motility and migration potentials of SW480 vs. SW620 cells, which is in line with the results described by Kubens et al. [18], namely, a higher spontaneous motility of SW480 vs. SW620 cells; and higher col-I SF and migration potentials of HCT116 p53 $3^{-/}$vs. HCT116 p $53^{+/+}$cells, which confirms what was reported in literature [20], namely, p53 loss associated with increased cell motility. RI increase in col-I SF potential has earlier been demonstrated for breast cancer cells with the focus on cell survival but not cell migration [16]. To the best of our knowledge, the findings presented here are the first reporting the direct relationship between increased col-I SF potential and migratory behaviors of cancer cells after X-radiation.

Our study results indicate that integrin $\beta 1$ is essential but not responsible for RI increase in col-I SF by colon cancer cells. In literature, multiple studies report an upregulation of integrin $\beta 1$ expression associated with the aggressive phenotype and invasion after $\mathrm{X}$-radiation $[9,12,21,22]$. Besides integrin $\alpha 2 \beta 1$, integrin $\alpha_{1} \beta_{1}$ is a mediator of col-I specific cell interactions. Li et al. [12] reported that integrin $\alpha$, was downregulated after radiation. Moreover, integrins $\alpha_{1} \beta_{1}$ and $\alpha 2 \beta 1$ have been reported with contrasting roles, suggesting that decreased integrin $\alpha_{1}$ might also favor the increased invasiveness of irradiated cells. Our study shows the differences in NMMII isoforms $\mathrm{A}, \mathrm{B}$ and $\mathrm{C}$ expressions between the different colon cancer cells, but indicates no change after irradiation except of a RI NMHCIIC expression in SW620 cells. NMHCIIB, which was expressed in SW620 only, is known to regulate cell polarity in non-migrating cells [23]. This observation suggests that NMHCIIB is a potential indicator of non-migrating cells in our in vitro model. Further, we determined a lower MLC2 expression in SW vs. HCT116 cells, and X-radiation resulted in increased and decreased MLC2 expressions in SW480 and HCT116 p53 $3^{++}$cells, respectively. These results for integrin $\beta 1$ and NMMIIrelated protein expression were further supported by our PCR results for sham vs. X-radiated SW480 and HCT116 p53 $3^{+++}$cells (see Supplementary Table 1). However, our protein expression results are not in line with the results described by Blockhuys et al. [16], namely, X-radiation of MCF-7/6 breast cancer cells resulted in increased
A

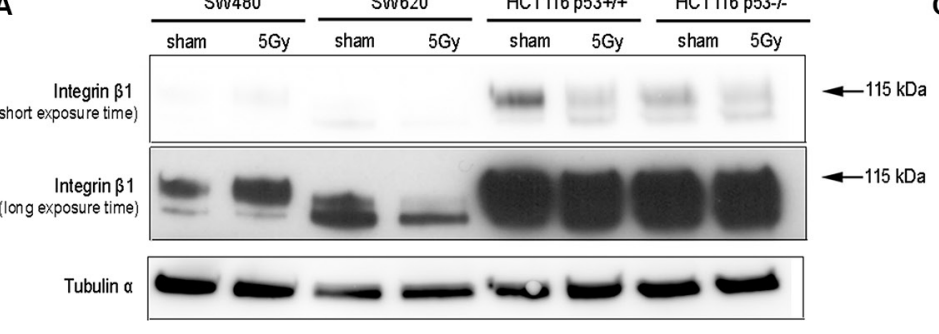

C
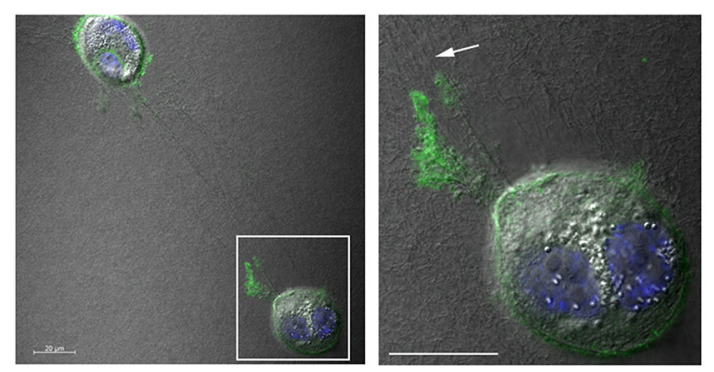

B
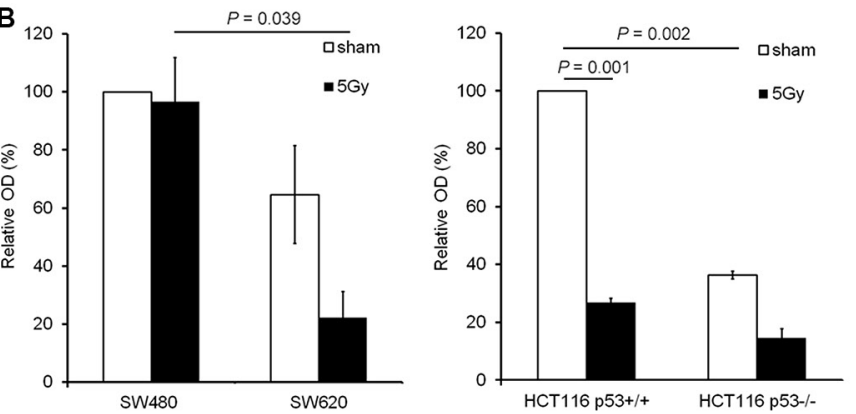
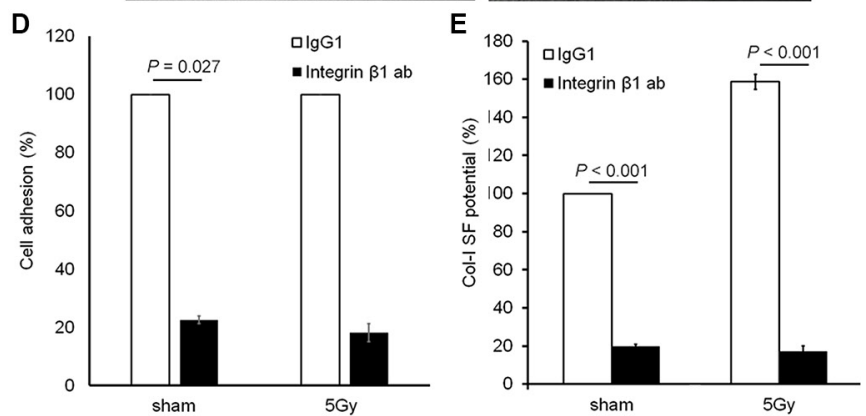

Figure 4: Integrin $\beta 1$ functionality was essential for col-I adhesion and col-I SF by colon cancer cells after X-radiation. (A and B) Representative blots (short and long exposure times) and quantitative results for integrin $\beta 1$ expression in the four colon cancer cell lines for sham and $5 \mathrm{~Gy} \mathrm{X}$-radiated conditions. Hereby, the mature form of integrin $\beta 1$ was quantified (arrows indicate the protein bands with molecular weight of $115 \mathrm{kDa})$. Tubulin $\alpha$ was used as loading control. Error bar represents the standard error of the mean $\left(n_{\text {IrExxp }}=3\right.$, $t$-test). (C) Visualization of total integrin $\beta 1$ expression and col-I fiber straps formed by 5 Gy X-radiated HCT116 $53^{+/+}$cells using confocal fluorescence microscopy and differential interference contrast microscopy, respectively (right panel shows framed area indicated in left panel; arrow indicates col-I SF at integrin $\beta 1$-rich tip of cell protrusion; scale bar $=20 \mu \mathrm{m}$ ). (D) Quantification of the col-I adhesion potential of HCT116 p53 $3^{+/+}$cells in sham or 5 Gy irradiated condition, after control (IgG1) or neutralizing integrin $\beta 1$ antibody $(10 \mu \mathrm{g} / \mathrm{mL})$ treatment. Error bar represents the standard error of the mean $\left(n_{I r E x p}=3\right)$. (E) Quantification of the col-I SF potential of HCT116 p53 $3^{++/}$cells in sham or 5 Gy X-radiated condition after control (IgG1) or neutralizing integrin $\beta 1$ antibody $(10 \mu \mathrm{g} / \mathrm{mL})$ treatment. Error bar represents the standard error of the mean $\left(n_{I r E x p}=3\right.$; $t$-test $)$. 
NMMIIA and MLC2 expression levels in parallel with their increased col-I SF potential. Our molecular study suggest that other cellular molecules are responsible for the RI increase in col-I SF and migration potentials of colon cancer cells. Vinculin, which was recently reported by Thievessen et al. [24] as regulator of traction force generation by cells in a $3 \mathrm{D}$ collagen without affecting myosin II, is a potential candidate protein.

NLM provided 3D visual, chemically and semiquantitative information about cell-induced col-I fiber straps. SHG and TPEF allowed 3D visualization of col-I and reactive oxygen species-positive colon cancer cells, respectively. Although SHG confirmed col-I specificity of the cell-induced fiber straps, only the thicker fibers within the straps could be visualized due to the lower resolution of our SHG set up (approximately $500 \mathrm{~nm}$ ) (see Supplementary Figure 5). Nonetheless, our study illustrated NLM as a useful tool in biological science and clinical practice.

In the future, we will aim to evaluate the clinical significance of col-I SF in the progression and treatment
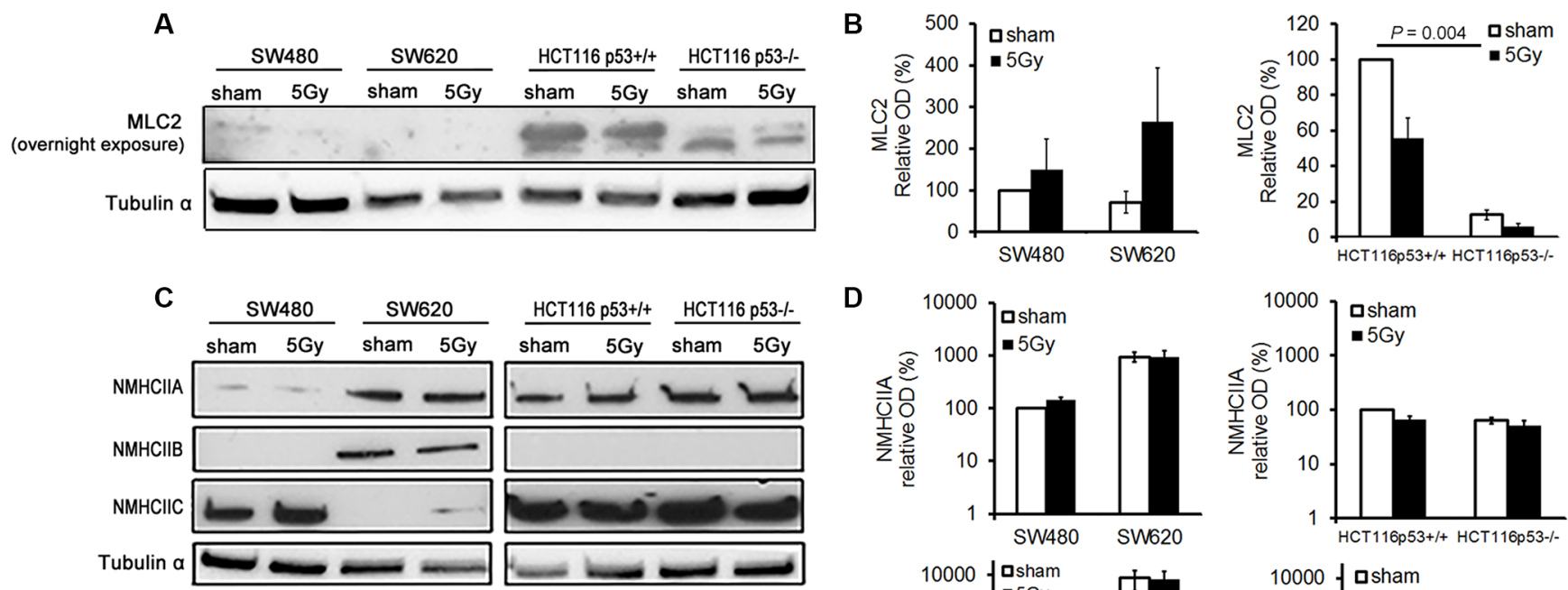

D
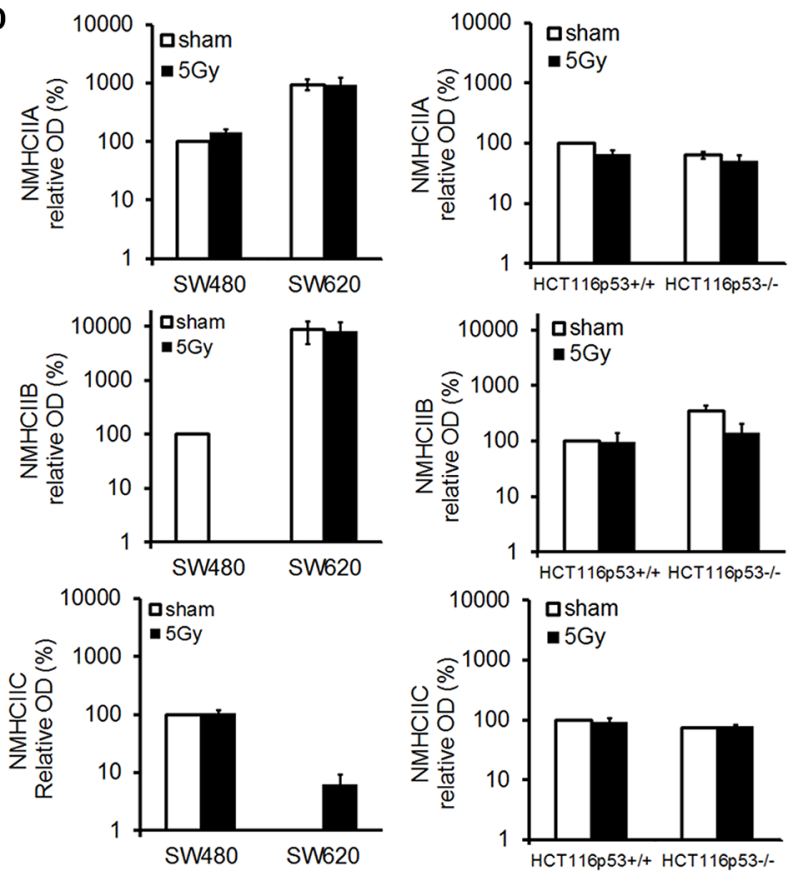

Figure 5: X-radiation did not induce significant changes in MLC2 and NMHCIIA, -B, and -C expression levels in the analyzed colon cancer cell lines. (A and B) Representative blot (overnight exposure time) and quantitative results for MLC2 expression. Tubulin $\alpha$ expression was used as loading control. Error bar represents the standard error of the mean $\left(n_{\text {IrExp }}=3\right)$. (C and $\left.\mathbf{D}\right)$ Representative blot and quantitative results for NMHCIIA, $-\mathrm{B}$, and $-\mathrm{C}$ expression levels. Tubulin $\alpha$ expression was used as loading control. Error bar represents the standard error of the mean $\left(n_{I r E x p}=3\right)$. (NMHCII, non-muscle myosin heavy chain II). 
lines were kindly provided by Professor Bert Vogelstein (Johns Hopkins University, Baltimore, MD). Both HCT116 cell lines were maintained at $37^{\circ} \mathrm{C}$ and $5 \% \mathrm{CO}_{2}$ in McCoy's 5A medium (modified) (GIBCO), supplemented with 10\% heat inactivated fetal bovine serum, $0.5 \%$ L-glutamine, and $1 \%$ penicillin/streptomycin cocktail.

\section{Antibodies}

The following antibodies were used: mouse IgG1 (MG100) from Life Technologies (Carlsbad, CA), antiintegrin $\beta 1$ P5D2 (ab24693) from Abcam (Cambridge, UK), anti-tubulin $\alpha$ (T9026) from Sigma-Aldrich, HRP-conjugated polyclonal goat anti-mouse or anti-rabbit antibodies from DAKO Cytomation (Glostrup, DK), and anti-integrin $\beta 1$ (\#4706), anti-MLC2 (\#3672), anti-NMHCIIA (\#3403), antiNMHCIIB (\#3404), anti-NMHCIIC (\#8189), Alexa Fluor ${ }^{\circledR}$ 488-conjugated anti-mouse $\mathrm{IgG}(\mathrm{H}+\mathrm{L})$ antibodies from Cell Signaling Technologies (Danvers, MA).

\section{X-radiation}

Cells were exposed to 5 Gy radiation dose of $6 \mathrm{MV}$ photon spectrum using a linear accelerator (Clinac 4/100, Varian, Palo Alto, CA) and evaluated 5 days later. The cells were positioned below $3 \mathrm{~cm}$ polymethyl methacrylate, $105 \mathrm{~cm}$ from the photon source (source-to-surface distance $(\mathrm{SSD})=100 \mathrm{~cm})$. The dose rate at the position of the cells was $4.8 \mathrm{~Gy} / \mathrm{min}$ and the field size at SSD was $30 \times 30 \mathrm{~cm}^{2}$. In contrast to the $\mathrm{X}$-radiated cells, the sham-treated cells were not exposed to X-rays. The $5 \mathrm{~Gy} \mathrm{X}$-radiation dose used in this study is a clinical relevant dose, as it is used for short-term radiotherapy of rectal cancer patients.

\section{Col-I based assays}

\section{Col-I matrix assay}

A single cell suspension $\left(10^{5}\right.$ cells $\left./ 1.5 \mathrm{ml}\right)$ was seeded on top of a col-I matrix $(1 \mathrm{mg} / \mathrm{ml})$ followed by an incubation period of $24 \mathrm{~h}$ at $37^{\circ} \mathrm{C}$ and $5 \% \mathrm{CO}_{2}$. Cell morphology and col-I remodeling were studied by an inverted PCM (AxioVert.A1, ZEISS; Software AxioVision 4.8). Col-I SF potential of the cells was calculated as the percentage of SF cells vs. the total number of adherent cells. Data was collected for three independent radiation experiments, with five randomly selected microscopic fields using a 10X objective [16].

\section{Stressed col-I matrix contraction assay [25]}

Single cells suspended in col-I gel solution (2 $\times 10^{5}$ cells $\left./ 300 \mu \mathrm{l}\right)$ were added into a well of a 24 -well plate. After gel polymerization, culture medium $(700 \mu \mathrm{l})$ was added on top of the cell-containing col-I gel. After an incubation period of $24 \mathrm{~h}$ the col-I gel was detached from the well and contraction was measured $24 \mathrm{~h}$ later $\left(\right.$ contraction index $\left.\left.(\%)=\left(\mathrm{D}_{\text {well }}-\mathrm{D}_{\text {col }}\right) / \mathrm{D}_{\text {well }}\right) \times 100\right)(\mathrm{D}$ $=$ diameter). Data was collected for two independent radiation experiments performed in duplicate.

\section{Cell adhesion assay (col-I coating)}

Single cell suspensions $\left(10^{5}\right.$ cells $\left./ 500 \mu \mathrm{L}\right)$ were seeded in col-I pre-coated wells of a 24 -well plate. After an incubation period of $90 \mathrm{~min}$ at $37^{\circ} \mathrm{C}$ and $5 \% \mathrm{CO}_{2}$, a standard crystal violet staining was performed and the number of adherent cells was quantified after PCM using ImageJ software. Data was collected for three independent radiation experiments performed in duplicate.

\section{Zone exclusion assay (col-I coating)}

Single cells suspended in $1 \%$ FBS $\left(1.5 \times 10^{5}\right.$

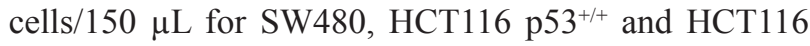
$\mathrm{p} 53^{-/-}$, and $5 \times 10^{5}$ cells $/ 150 \mu \mathrm{L}$ for SW620) were seeded in col-I pre-coated wells of the zone-exclusion assay (Oris ${ }^{\mathrm{TM}}$ migration assay-Collagen I coated, Amsbio). Cell stoppers were removed after an incubation period of $8 \mathrm{~h}$ at $37^{\circ} \mathrm{C}$ and $5 \% \mathrm{CO}_{2}$. Wound closure was evaluated after another $24 \mathrm{~h}$ of incubation using PCM (BX41, Olympus). The migration index $(\%)$ was calculated as $\left(\mathrm{D}_{\text {control }}-\mathrm{D}_{\text {test }}\right)$ / $\left.\mathrm{D}_{\text {control }}\right) \times 100(\mathrm{D}=$ diameter $)$. Data was collected for three independent radiation experiments performed in duplicate.

\section{Integrin $\beta 1$ neutralization}

Single cell suspensions were pretreated for $1 \mathrm{~h}$ under motion at $37^{\circ} \mathrm{C}$ in serum-free culture medium supplemented with $10 \mu \mathrm{g} / \mathrm{mL}$ mouse IgG1 (isotype control) or $10 \mu \mathrm{g} / \mathrm{mL}$ integrin $\beta 1$ neutralizing antibody.

\section{Western blot}

Proteins were extracted by lysis buffer containing $150 \mathrm{mM} \mathrm{NaCl}, 2 \%$ Triton, $0.1 \%$ SDS, $50 \mathrm{mM}$ Tris $\mathrm{pH}$ 8.0, protease inhibitor cocktail (ROCHE, Basel, $\mathrm{CH}$ ) and phospatase inhibitor cocktail (ROCHE) and stored at $-20^{\circ} \mathrm{C}$. Protein concentration was determined by the colorimetric BCA protein assay reagent (Pierce, Woburn, MA). Equal amounts of protein for each sample were subjected to SDS/PAGE and transferred onto nitrocellulose membranes (Whatman, Boston, MA). Membranes were first probed with primary antibodies and subsequently with HRP-conjugated secondary antibodies. Protein bands were detected using ECL plus Western Blotting Detection System (GE Healthcare, Piscataway, NJ).

\section{Immunofluorescence staining}

Cells seeded on top of a col-I gel were fixed and prepared for immunofluorescence staining as described 
by Abe et al. [26]. Shortly, samples were fixed with 4\% paraformaldehyde (PFA), blocked with $1 \%$ glycine $/ 2 \%$ BSA/ PBS and permeabilized in $0.5 \%$ Triton-X-100/ phosphate buffered saline (PBS). Samples were then incubated with primary antibody diluted in $1 \% \mathrm{BSA} / \mathrm{PBS}$ for $1.5 \mathrm{~h}$. After washing, samples were incubated in secondary antibody diluted in $1 \%$ BSA/PBS for $1 \mathrm{~h}$. Samples were washed, stained with DAPI, mounted and analyzed with confocal microscopy.

\section{Microscopy}

\section{Confocal microscopy}

Confocal images were captured with a Zeiss Axio Imager.Z2 equipped with a LSM700 confocal module (ZEN software) using a $63 \mathrm{X} / 1.4 \mathrm{NA}$ oil immersion objective.

\section{Scanning electron microscopy (SEM)}

SEM was performed using a JEOL JSM-6320F operated at $10 \mathrm{kV}$. Collagen gels plus cells were fixed with $4 \%$ PFA in PBS for $1 \mathrm{~h}$ at room temperature. The fixed samples were dehydrated in a graded distilled water/ethanol series: $30 \%, 50 \%, 70 \%$, and $100 \%$ for 15 min each, followed by washes with a graded ethanol/ hexamethyldisilazane series: $30 \%, 50 \%, 70 \%$, and $100 \%$ for $15 \mathrm{~min}$ each, and finally allowed to dry overnight. This drying procedure has been employed to avoid sample shrinkage [27]. The collagen matrix was sputter-coated with approximately $14 \mathrm{~nm}$ platinum prior to SEM. SEM images were taken at multiple locations across the sample and used to qualitatively assess the col-I fiber alignment induced by the cells.

\section{Non-linear microscopy (NLM) [28]}

A PFA-fixed sample was mounted with fluorescence mounting medium (DAKO) on a microscope slide covered with a $0.17 \mathrm{~mm}$ coverslip. Two laser beams of synchronized pico-second pulse trains in the near-infrared wavelength regimes were spatially and temporally overlapped and coupled into an inverted microscope. Simultaneous illumination of the sample with laser beams at wavelengths of $817 \mathrm{~nm}$ and $1064 \mathrm{~nm}$ induced the SHG and TPEF processes in our sample with combined imaging of col-I and cells, respectively. The laser beams were focused on the samples using a 40x objective (Nikon Plan Fluor N.A. 1.3, working distance $0.21 \mathrm{~mm}$ ), and emitted SHG and TPEF signals were registered by singlephoton-counting photomultiplier tubes in transmission and reflection mode, respectively. Bandpass filters 405/10 and $514 / 30$ were used to isolate the SHG and TPEF signals, respectively. Typical average excitation powers at the samples were $5 \mathrm{~mW}$ and $6 \mathrm{~mW}$ for laser beams $817 \mathrm{~nm}$ and $1064 \mathrm{~nm}$, respectively. Simultaneous SHG and TPEF microscopy z-stacks covered an area of $127.9 \times 127.9 \mu \mathrm{m}^{2}$ and a depth of $25 \mu \mathrm{m}$ ( step size $=0.2 \mu \mathrm{m})$. The image acquisition time at each position was $12.4 \mathrm{sec}$. Merged SHG and TPEF images and volume views showing the cells on col-I matrix were processed using the ImageJ "Volume Viewer" plugin.

\section{Phase-contrast video-microscopy}

Cells were seeded on the col-I matrices at a density of $1 \times 10^{5}$ cells/well in $2.5 \mathrm{~mL}$ of standard growth medium, and time-lapses were started after an incubation period of $30 \mathrm{~min}$. Phase-contrast images were acquired using a LSM700 confocal mounted on a Zeiss Observer Z1 (Jena, Germany), controlled by Zeiss Zen (2012) software. Multi-position, time-lapse images were captured with $120 \mathrm{sec}$ interval for $15 \mathrm{~h}$ at $37^{\circ} \mathrm{C}$ and $5 \% \mathrm{CO}_{2}$. Images were captured with a phasecontrast $10 \mathrm{X} / 0.25$ NA objective. For the analysis, every cell in each movie that remained within the field-ofview during the entire time-series was tracked using the Manual tracking tool (point-click mode) provided by ImageJ software. In each case, the cell centroid, defined as a half point along the long distance of the cell, was used for tracking. Data were exported into Ibidi's "Chemotaxis and Migration" tool for the Wind-Rose plot representation of the tracks and the determination of the parameters speed (= accumulated distance/time), accumulated - and Euclidean distances.

\section{Statistical analysis}

Statistical analysis of paired observations was conducted using the Student's $t$-test, whereby the threshold level of significance was set to 0.05 .

\section{CONFLICTS OF INTEREST}

There are no conflicts of interest.

\section{FUNDING}

This study was funded by the Swedish Cancer Foundation, Swedish Research Council, the Wallenberg Foundation and the Health Research Council in SouthEast Sweden.

\section{REFERENCES}

1. Pahlman L. Indications for neoadjuvant long-term radiotherapy. Recent Results Cancer Res. 2005; 165:212-220.

2. Kapiteijn E, Marijnen CA, Nagtegaal ID, Putter H, Steup WH, Wiggers T, Rutten HJ, Pahlman L, Glimelius B, van Krieken JH, Leer JW, van de Velde CJ, Dutch Colorectal 
Cancer Group. Preoperative radiotherapy combined with total mesorectal excision for resectable rectal cancer. N Engl J Med. 2001; 345:638-646.

3. Improved survival with preoperative radiotherapy in resectable rectal cancer. Swedish Rectal Cancer Trial. N Engl J Med. 1997; 336:980-987.

4. Von Essen CF. Radiation enhancement of metastasis: a review. Clin Exp Metastasis. 1991; 9:77-104.

5. Moncharmont C, Levy A, Guy JB, Falf AT, Guilbert M, Trone JC, Alphonse G, Gilormini M, Ardail D, Toillon RA, Rodriguez-Lafrasse C, Magné N. Radiation-induced cell migration/invasion process: a review. Crit Rev Oncol/ Hematol. 2014; 92:133-142.

6. Mehlen P, Puisieux A. Metastasis: a question of life or death. Nat Rev Cancer. 2006; 6:449-458.

7. Friedl P, Wolf K. Plasticity of cell migration: a multiscale tuning model. J Cell Biol. 2010; 188:11-19.

8. Friedl P, Bröcker EB, Zänker KS. Integrins, cell matrix interactions and cell migration strategies: fundamental differences in leukocytes and tumor cells. Cell Adhes Commun. 1998; 6:225-236.

9. Klein CE, Dressel D, Steinmayer T, Mauch C, Eckes B, Krieg T, Bamkert RT, Weber L. Integrin alpha 2 beta 1 is upregulated in fibroblasts and highly aggressive melanoma cells in three-dimensional collagen lattices and mediates the organization of collagen I fibrils. J Cell Biol. 1991; 115:1427-1436.

10. Yao H, Zeng ZZ, Fay KS, Veine DM, Staszewski ED, Morgan M, Wilder-Romans K, Williams TR, Spalding AC, Ben-Josef E, Livant DL. Role of $\alpha 5 \beta 1$ integrin up-regulation in radiation-induced invasion by human pancreatic cancer cells. Transl Oncol. 2011; 4:282-292.

11. Gogineni VR, Nalla AK, Gupta R, Gujrati M, Klopfenstein JD, Mohanam S, Rao JS. $\alpha 3 \beta 1$ integrin promotes radiation-induced migration of meningioma cells. Inter J Oncology. 2011; 38:1615-1624.

12. Li $\mathrm{X}$, Ishihara $\mathrm{S}$, Yasuda $\mathrm{M}$, Nishioka $\mathrm{T}$, Mizutani $\mathrm{T}$, Ishikawa M, Kawabata K, Shirato H, Haga H. Lung cancer cells that survive ionizing radiation show increased integrin a2ß1- and EGFR-dependent invasiveness. PloS One. 2013; 8:e70905.

13. Vicente-Manzanares M, Ma X, Adelstein RS, Horwitz AR. Non-muscle myosin II takes centre stage in cell adhesion and migration. Nat Rev Mol Cell Biol. 2009; 10:778-790.

14. Hindman B, Goeckeler Z, Sierros K, Wysolmerski R. Nonmuscle myosin II isoforms have different functions in matrix rearrangement by MDA-MB-231 cells. PLoS One. 2015; 10:e131920.

15. Jana SS, Kawamoto S, Adelstein RS. A specific isoform of nonmuscle myosin II-C is required for cytokinesis in a tumor cell line. J Biol Chem. 2006; 281:24662-24670.
16. Blockhuys S, Van Rompaye B, De Rycke R, Lambein K, Claes K, Bracke M, De Wagter C, De Wever O. Radiationinduced myosin IIA expression stimulates collagen type I matrix reorganization. Radiother Oncol. 2013; 108:162-167.

17. Leibovitz A, Stinson JC, McCombs WB, McCoy C, Mazur KC, Mabry ND. Classification of human colorectal adenocarcinoma cell lines. Cancer Res. 1976; 36:4562-4569.

18. Kubens BS, Zänker KS. Differences in the migration capacity of primary human colon carcinoma cells (SW480) and their lymph node metastatic derivatives (SW620). Cancer Lett. 1998; 131:55-64.

19. Bunz F, Dutriaux A, Lengauer C, Waldman T, Zhou S, Brown JP, Sedivy JM, Kinzler KW, Vogelstein B. Requirement for $\mathrm{p} 53$ and $\mathrm{p} 21$ to sustain $\mathrm{G} 2$ arrest after DNA damage. Science 1998; 282:1497-1501.

20. Muller PAJ, Vousden KH, Norman JC. P53 and its mutants in tumors cell migration and invasion. J Cell Biol. 2011; 192:209-218.

21. Ishihara S, Haga H, Yasuda M, Mizutani T, Kawabata K, Shirato $\mathrm{H}$, Nishioka $\mathrm{T}$. Integrin $\beta 1$-dependent invasive migration of irradiation-tolerant human lung adenocarcinoma cells in 3D collagen matrix. Biochem Biophys Res Commun. 2010; 396:651-655.

22. Nalla AK, Asuthkar S, Bhoopathi P, Gujrati M, Dinh D, Rhao JS. Suppression of uPAR retards radiation-induced invasion and migration mediated by integrin $\beta 1 / F A K$ signaling in medulloblastoma. PLoS ONE 2010; 5:e13006.

23. Lo CM, Buxton D, Chua G, Dembo M, Adelstein R, Wang YL. Nonmuscle Myosin IIB is involved in the guidance of fibroblast migration. Mol Biol Cell. 2004; 15:982-989.

24. Thievessen I, Fakhri N, Steinwachs J, Kraus V, McIsaac RS, Gao L, Chen BC, Baird MA, Davidson MW, Betzig E, Oldenbourg R, Waterman CM, Fabry B. Vinculin is required for cell polarization, migration, and extracellular matrix remodeling in 3D collagen. FASEB J 2015; 29:4555-4567.

25. Grinnell F. Fibroblast-collagen-matrix contraction: growthfactor signalling and mechanical loading. Trends Cell Biol. 2000; 10:362-365.

26. Abe M, Ho CH, Kamm KE, Grinnell F. Different molecular motors mediate platelet-derived growth factor and lysophosphatidic acid-stimulated floating collagen matrix contraction. J Biol Chem. 2003; 278:47707-47712.

27. Xu B, Chow MJ, Zhang Y. Experimental and modelling study of collagen scaffolds with the effects crosslinking and fiber alignment. Int J Biomater. 2011; 2011:172389-172400.

28. Brackmann C, Zaborowska M, Sundberg J, Gatenholm P, Enejder A. In situ imaging of collagen synthesis by osteoprogenitor cells in microporous bacterial cellulose scaffolds. Tissue Eng Part C Methods. 2012; 18:227-234. 